Article

\title{
A Bio-Economic Analysis of the Liberian Coastal Fisheries
}

\author{
Alvin Slewion Jueseah ${ }^{1, *}$, Dadi Mar Kristofersson ${ }^{1}$, Tumi Tómasson ${ }^{2}$ and \\ Ogmundur Knutsson ${ }^{3}$ \\ 1 Department of Economics, School of Social Sciences, University of Iceland, Sæmundargötu 2, \\ 101 Reykjavík, Iceland; dmk@hi.is \\ 2 UNESCO GRÓ-Fisheries Training Program, Marine and Freshwater Research Institute, \\ 220 Hafnarfjörður, Iceland; tumi@groftp.is \\ 3 Directorate of Fisheries, Dalshrauni 1, 220 Hafnarfjörður, Iceland; o.knutsson@gmail.com \\ * Correspondence: a.slewionjueseah@gmail.com or asj56@hi.is; Tel.: +354-764-7113
}

Received: 24 October 2020; Accepted: 22 November 2020; Published: 25 November 2020

check for updates

\begin{abstract}
Many coastal fisheries are subject to harvesting externalities due to inadequate regulations compounded by limited enforcement. Coastal fisheries in Liberia consist of a fleet of dugout canoes (Kru) primarily targeting demersal finfish, larger open wooden boats propelled with outboard engines targeting small inshore pelagics (Fanti), and a small number of industrial trawlers employing midwater and bottom trawls targeting finfish and shrimp. This paper develops a bio-economic model for the coastal fisheries in Liberia and employs the model to identify economic optimal fishing effort and harvesting trajectories for the different coastal fleets. The results show under harvesting and disinvestments in the coastal fisheries in Liberia. In 2010 the Government of Liberia declared a six nautical mile inshore exclusion zone accessible only to small-scale fisheries (SSF), which was accompanied by increased enforcement. The coastal fleets in 2016 were profitable but the distribution of profits was tilted to the small-scale fleets. The government needs to evaluate what policy options are available to fully utilize the fisheries potential for different species complexes while at the same time reduce the risk of conflict and overharvesting. There appears to be a need for investment in new technologies, which can only take place if fishing in Liberia will remain profitable.
\end{abstract}

Keywords: bio-economic modelling; coastal fisheries; SDG 14; profits; Liberia

\section{Introduction}

Liberia is among the poorest countries in the world and fisheries account for about $10 \%$ of GDP [1,2]. It has an exclusive economic zone (EEZ) of about $246.000 \mathrm{~km}^{2}$ and a continental shelf that ranges in width from 16 to $56 \mathrm{~km}$ [3]. The fishery resources are currently exploited by offshore and coastal fleets [4]. Potential yield has been estimated at around 40.000 tons year $^{-1}[3,4]$ but total catch $^{2}$ between 2013-2016 averaged around 26,700 tons (Table 1). 
Table 1. Summary statistics of fisheries data 2013-2016.

\begin{tabular}{|c|c|c|c|c|c|}
\hline Stocks & Statistics & Kru Boats & Fanti Boats & Ind. Vessels & $\begin{array}{l}\text { Standardized CPUE } \\
\text { (ton boat }^{-1} \text { year }^{-1} \text { ) }\end{array}$ \\
\hline \multirow{4}{*}{$\begin{array}{l}\text { Small pelagic } \\
\left(\text { tons year }^{-1}\right)\end{array}$} & Mean & 1043.5 & $16,286.7$ & 86.2 & 5.9 \\
\hline & Std Dev & 451.7 & 2355.3 & 73.1 & 1.4 \\
\hline & Min & 656.1 & $14,048.8$ & 12.5 & 4.6 \\
\hline & Max & 1626.5 & $19,142.7$ & 166.1 & 7.3 \\
\hline \multirow{4}{*}{$\begin{array}{l}\text { Medium pelagic } \\
\left(\text { tons year }^{-1} \text { ) }\right.\end{array}$} & Mean & 990.4 & 3501.7 & 2.5 & 1.4 \\
\hline & Std Dev & 252.2 & 705.5 & 2.1 & 0.4 \\
\hline & Min & 747.9 & 2568.4 & 0.4 & 0.9 \\
\hline & Max & 1324.0 & 4162.7 & 4.8 & 1.8 \\
\hline \multirow{4}{*}{$\begin{array}{l}\text { Shallow-water demersal } \\
\quad\left(\text { tons year }^{-1}\right)\end{array}$} & Mean & 1842.1 & 390.7 & 129.8 & 0.6 \\
\hline & Std Dev & 245.2 & 58.5 & 72.5 & 0.1 \\
\hline & Min & 1518.5 & 350.9 & 22.5 & 0.5 \\
\hline & Max & 2088.7 & 477.4 & 178.6 & 0.8 \\
\hline \multirow{4}{*}{$\begin{array}{l}\text { Deep-water demersal } \\
\quad\left(\text { tons year }^{-1}\right)\end{array}$} & Mean & 1055.2 & 85.4 & 159.1 & 0.4 \\
\hline & Std Dev & 858.1 & 62.9 & 126.8 & 0.2 \\
\hline & Min & 138.0 & 11.9 & 34.8 & 0.1 \\
\hline & Max & 2178.0 & 165.2 & 313.5 & 0.6 \\
\hline \multirow{4}{*}{ Crustacean (tons year ${ }^{-1}$ ) } & Mean & 342.7 & 2.9 & 45.8 & 0.1 \\
\hline & Std Dev & 70.8 & 2.3 & 50.8 & 0.0 \\
\hline & Min & 277.6 & 0.5 & 5.0 & 0.1 \\
\hline & Max & 425.0 & 6.0 & 116.0 & 0.1 \\
\hline \multirow{4}{*}{$\begin{array}{l}\text { Large pelagic } \\
\left(\text { tons year }^{-1} \text { ) }\right.\end{array}$} & Mean & 353.1 & 389.4 & 7.2 & -1 \\
\hline & Std Dev & 198.1 & 118.7 & 12.6 & - \\
\hline & Min & 184.5 & 238.8 & 0.1 & - \\
\hline & Max & 640.0 & 528.3 & 26 & - \\
\hline \multirow{4}{*}{ Effort (no. of boats year ${ }^{-1}$ ) } & Mean & 2922 & 753 & 4 & - \\
\hline & Std Dev & 283 & 78 & 2 & - \\
\hline & Min & 2615 & 685 & 1 & - \\
\hline & Max & 3163 & 827 & 7 & - \\
\hline Years observed & & 4 & 4 & 4 & - \\
\hline
\end{tabular}

Source: NaFAA Statistics; ${ }^{1}$ not included in the analysis.

While the coastal industrial fishery is subject to strict entry regulations and other management measures, the small-scale fisheries (SSF) are basically open access [5]. Open access fisheries have been reported to be generally characterized by problems of overexploitation and poor economic performance [6,7]. Only a few coastal nations have instituted proper fishery management systems to address this issue [6,7]. Although most commercial fishery resources have the potential to generate substantial profits, a relatively small number of fisheries are therefore profitable [7].

In this paper, a bio-economic model is developed and used to evaluate the fisheries and identify economically feasible fishing effort and harvesting trajectories for the main coastal fleets operating in Liberia. The main research questions are: What is the current state of the coastal fisheries and how could management of the resource be better aligned with the United Nations Sustainable Development Goal (SDG) 14 targets 14.4 and 14B? According to SDG 14.4 fishing should be effectively regulated and overfishing, illegal, unreported, and unregulated fishing, as well as destructive harvesting practices, brought to an end and science-based management plans implemented. SDG target 14.B refers to giving SSF fishers access to marine resource and markets [8]. The final research question is what are the economic outcomes of the coastal fleets?

\section{Background}

The offshore fishery in Liberia primarily consists of large industrial tuna vessels mainly from the EU which operate under fisheries partnership access agreement. They employ purse seines, longlines 
and pole and line. The catch, estimated at around 10,000 tons year ${ }^{-1}$ according to National Fisheries and Aquaculture Authority (NaFAA) statistics, is not landed in Liberia.

The coastal fisheries, which are the focus of this paper, are conducted on the continental shelf. The shelf is on average $36 \mathrm{~km}$ wide, narrower in the north between Monrovia and Robertsport with trawling grounds down to $800 \mathrm{~m}$ and wider in the south between Monrovia and the Ivory Coast [3]. The waters are stratified and warm $\left(>24^{\circ} \mathrm{C}\right)$ with low salinity levels $\left(<35^{\circ} / 00\right)$ [3]. The coastal fisheries are affected by the seasonal oscillation of the thermocline and relatively low nutrients

Six exploitable species assemblages have been identified i.e., small, medium, and large pelagics, shallow- and deep-water demersals and crustaceans [4], which are targeted to a different extent by the small-scale and industrial fleets. SSF include the Kru-non-motorized dugout canoes generally 5-7 m long with 1-3 crewmembers-and the Fanti-larger open wooden boats 10-15 $\mathrm{m}$ long propelled by outboard engines with a crew of 6-26-who have exclusive access up to six nautical miles (nm) offshore but may fish further out as well. Kru operators use handlines and gillnets and target demersal species like cassava fish (Pseudotolithus spp.), butternose (Galeodes decadactylus), solefish (Cynoglossus spp.) above the thermocline and groupers (Epinephalus spp.), snappers (Lutjanus spp.), and grunters (Pomadasys spp.) [9] below the thermocline. Operators of Kru canoes also target some crustaceans mainly crabs and lobsters, using gill nets and traps.

The Fantis boats are mainly operated by foreigners from Ghana [10] and they primarily use ring nets and target small pelagics like bonny (Sardinella spp.), porjoe (Chloroscombrus chrysurus), and Atlantic flying fish (Cheilopogon melanurus) [4]. Both Kru and Fanti also catch large and medium pelagics, as well as crustaceans, but to a much lesser extent.

The SSF provide livelihoods for around 10,800 full-time fishers and 22,100 local and foreign fish processors and traders $[10,11]$. Most of the catch is landed during the dry season, in October-April, when the weather is good the sea is calm and fishing conditions are favorable. During the rainy season, May-October, periods of strong ocean currents, heavy storms and rainfall limit the ability of the fleets to go out to sea [12].

The coastal industrial fishery comprises of trawlers that deploy mid-water and bottom trawls targeting the shallow- and deep-water demersal species as well as shrimps [12]. The vessels are owned by foreigners mainly from Europe (e.g., Spain, Greece, Russia.) and China, who operate through joint ventures with Liberian registered fishing agencies [12-14].

In the early $80 \mathrm{~s}, 14$ coastal industrial trawlers operated in Liberia mainly targeting shrimps with an annual catch of 746 tons in $1980[3,15]$. During this period, the industrial shrimp fishery was profitable. Maximum economic profits of the 14 trawlers were estimated at around 5.7 million \$ [15]. Due to the concentration of shrimps and demersal species in the inshore areas, the trawlers and small-scale fishers came into constant conflict, with the trawlers oftentimes destroying the fishing equipment of the small-scale fishers $[15,16]$.

Shortly after the civil war ended in 2006, almost 40 industrial vessels were in the coastal waters. However, since 2008, there has been a sharp decline and today there are only two such vessels operating in Liberian waters. The coastal industrial fleet size, during the periods of the social unrest, more than doubled in the 1980s [15], a development that seems to be associated with a lack of effective governance. Between 2013 and 2016, there were on average four coastal licensed industrial vessels, averaging about 180 Gross Registered Tonnage (GRT). This decrease in the number of trawlers appears to be due to the establishment of an Inshore Exclusion Zone (IEZ). The catch, whole-fish and shrimp frozen onboard, is supplied to the domestic market, although a part is also exported [12,13].

In 2010, the Liberian Government initiated key fisheries management reforms, with funding from the World Bank West African Regional Fisheries Program [10,17]. A six nm IEZ was introduced to protect the SSF [5]. This was the initial step to control illegal coastal industrial vessels from operating in the inshore zone and allow the commercial fishery resources to rebuild $[10,18]$. To secure the IEZ, the Government of Liberia established a Fisheries Monitoring Center (FMC) to monitor and control industrial fishing activities. Since then there have been no new investments in this fishery, while there 
has been an expansion of the Kru fisheries which seems to be consistent with growth trend after the war ended (Figure 1).

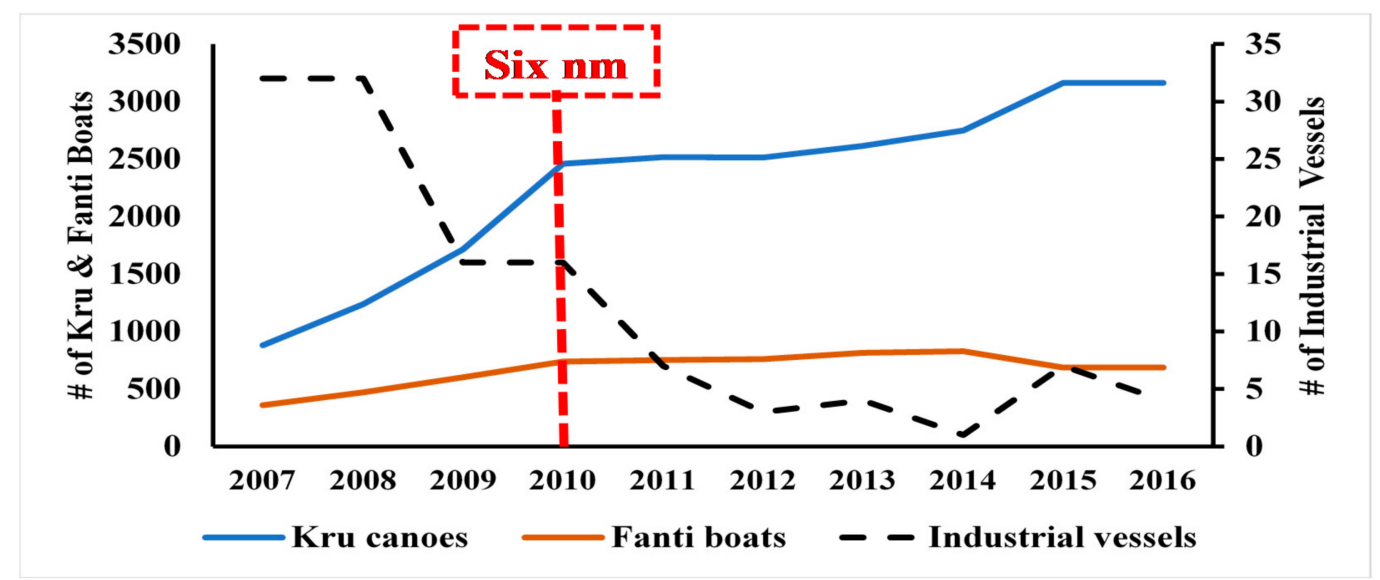

Figure 1. Liberian coastal fleets development trend. Source: National Fisheries and Aquaculture Authority.

\section{Analytical Approach}

An aggregative bio-economic model for different species assemblages, following the approach of Arnason [6] and World Bank [7], is used in this analysis. It is a discrete-time dynamic model that follows standard fisheries economic theory see [6,19-24]. The model encompasses three primary functions basic to any fisheries bio-economic model: the natural growth function $G(x)$, the harvest function $H(e, x)$, and the cost function $C(e)[6,7]$. The basic functional relationships of the model are as follow:

$$
\begin{gathered}
\dot{x}_{t}=G\left(x_{t}\right)-h_{t} \text { [Net biomass growth function] } \\
h_{t}=H\left(e_{t}, x_{t}\right) \text { [Harvesting function] } \\
\pi_{\mathrm{t}}=p_{\mathrm{t} \times} H\left(e_{t}, x_{t}\right)-\mathrm{C}\left(e_{t}\right) \text { [Net benefits function] }
\end{gathered}
$$

Equation (1) describes the instantaneous change in biomass as a function of natural growth $G\left(x_{t}\right)$ denoted by the derivative, $\dot{\mathrm{x}} \equiv \partial x / \partial t$, and harvest, $h$. The instantaneous change in biomass, $\dot{x}$, is approximated in discrete time with $\dot{x} \equiv x(t+1)-x(t)$. Expression (2) describes harvest as a function of fishing effort, $e$, and stock size, $x$, while expression (3) defines the net benefits as a function of harvest, prices $(p)$, and fishing costs, $C(e)$. Equilibrium in the model is characterized by stable biomass, $\dot{x}=0$. Following Arnason [6] and World Bank [7] expressions (1) and (2) can be reduced to $G\left(x_{t}\right)=H\left(e_{t}, x_{t}\right)$ in equilibrium.

\section{Empirical Model}

Following Arnason [6] and World Bank [7], a quadratic functional form [25] is assumed for the biomass growth function, $G(x)$, in expression (1) and is given as:

$$
G\left(x_{t}\right)=\alpha \times x_{t}-\beta \times x_{t}^{2}
$$

where $\alpha$ and $\beta$ are parameters. The parameter $\alpha$ measures the intrinsic growth rate of the biomass. It is easy to verify that the biomass carrying capacity $\left(X_{\max }\right)$ is the ratio of $\alpha / \beta$. In discrete-time, the change in biomass is approximated using the expression:

$$
x_{t+1}-x_{t}=\alpha \times x_{t}-\beta \times x_{t}^{2}
$$


where the biomass at $t+1$ less the biomass at time $t$ less harvest is used to identify biomass growth. For the harvesting function, a generalization of a Schaefer harvest function [26] is assumed as:

$$
h_{t}=\delta \times e_{t} \times x_{t}{ }^{\mu}
$$

where $\delta$ is the catchability coefficient and $\mu$ represents the schooling behaviour of the stock (usually $\mu \in[0,1])[6,7,21]$. For the net benefit function, the following functional form is specified:

$$
\pi_{t}=(1-\gamma) \times\left(p_{t} \times \delta \times e_{t} \times x_{t}^{\mu}\right)-\left(a_{t} \times e_{t}+\mathrm{fc}_{t}\right)
$$

where $\gamma$ is the crew's share (or bonus) of the fishing revenues, $p$ the unit ex-vessel price of the landings, $a$ is the unit marginal variable cost of fishing effort and $f_{C}$ the fixed costs. Expressions (4)-(7) should be regarded as the empirical counterparts of the general model, expressions (1)-(3). It is, however, not possible to estimate the empirical model because detailed stock assessments are not available for the species assemblages described earlier.

In empirical fisheries bio-economic models, proxies such as catch per unit of effort (CPUE) can be used for stock size [27-29]. Following Zhang and Smith [29], we designate CPUE such that $y_{t}=h_{t} / e_{t}$. From expression (6) CPUE is proportional to the stock size- $x_{t}=y_{t} / \delta$. The conventional method substitutes this proxy, in expression (5), simplifies and adds an error term [29]. The result is an empirical version of expression (5), for estimating $\alpha, \beta$ and $\delta$, using CPUE as an index of abundance and given as:

$$
\Delta y_{t}=b+c \times y_{t}+d \times e_{t}+\varepsilon_{t}
$$

where $b=\alpha, c=-(\beta / \delta) \leftrightarrow \beta=-(c \times \delta), d=-\delta \leftrightarrow \delta=-d$ and $\varepsilon_{t}$ is the error term. The error term is assumed to be independent and identically distributed (i.i.d) normal with zero mean and variance $\sigma_{\varepsilon}^{2}\left(\varepsilon_{t} \sim\right.$ i.i.d $N\left(0, \sigma_{\varepsilon}{ }^{2}\right)$. Expression (8) is then estimated by regression analysis. The relative effort factor is obtained by the average catch of fleet $i$ of species assemblage $j$ at time $t$ divided by the average catch of all fleets for species assemblage $j$ at time $t$. of the relative effort factor of fleet $i$ compared to a standardized vessel at time $t$ was calculated as the mean of the average catch ratio $(w=$ cpue) for the three fleets for each species assemblage $j$. The aggregate standardized fishing effort $e_{j t}{ }^{s}$ of all fleets for species assemblage $j$ is the sum of the product of the fishing power and fleet $i$ at time $t$. These are respectively specified as

$$
f_{i j t}=w_{i j t} / w_{s j t}
$$

The aggregate standardized fishing effort $e_{j t}{ }^{s}$ of all fleets for species assemblage $j$ is the sum of the product of the fishing power and fleet $i$ at time $t$ as specify below

$$
e_{j t}{ }^{s}=\sum_{I} f_{i j t} \times e_{i t}
$$

And substituting $e_{j t}{ }^{s}$ in expression (8) yields

$$
\Delta y^{s}{ }_{j t}=b_{j}+c_{j} \times y_{j t}+d_{j} \times\left(e_{j t}^{s}\right)+\varepsilon_{j t}
$$

After estimating (11), using the available data, maximum sustainable yield (MSY), MSY biomass $\left(X_{m s y}\right)$ and $X_{m a x}$ were calculated based on the expression (12) which were derived from expression (4).

$$
M S Y=\alpha^{2} /(4 \times \beta), X_{m s y}=\alpha /(2 \times \beta), X_{\max }=\alpha / \beta
$$




\section{Model Parameters Estimation}

\subsection{Data}

The bio-economic model, defined by Equations (4)-(7), consists of unspecified biological and economic parameters that must be estimated to make the model operational. The biological parameters include $\alpha, \beta, \delta$, and $\mu$ in the biomass growth and harvesting functions. The economic parameters in the net benefits function are $p, \gamma, a$, and $f c$. The coastal fishery is studied for a certain base year $\left(t^{*}\right)$. The base-year considered here is 2016 (i.e., $t^{*}=2016$ ). The biological (catch and effort) and economic data used in this analysis were obtained from multiple sources. It was only in 2013 that fisheries data collection was made more systematic. Catch data from the SSF are based on a stratified sampling program [4], while the catch data for the coastal industrial fishery are collected and reported by fisheries observers.

\subsubsection{Catch and Effort Data}

Data on total landed volume (aggregated by species assemblage), fishing effort, for the period 2013-2016, available biomass estimates, and schooling coefficients were employed to make the model operational. The total catch and fishing effort year ${ }^{-1}$ were obtained from NaFAA used in the calculation of total standardized effort and CPUE (tons boat ${ }^{-1}$ year $^{-1}$ ) for the fleets (Table 1). These were used in the estimation of $\alpha, \beta$, and $\delta$ in expression (11), which defines implicitly MSY, $X_{m s y}$ and $X_{\max }$. The assumed base-year biomass estimates for small and medium pelagics, shallow- and deep-water demersals species assemblages were drawn from MRAG [4], while for the crustaceans it was estimated using average standardized CPUE divided by the estimated $\delta$, for the data period. The schooling parameter estimates were obtained from Arnason and MRAG [30].

The number of Kru and Fanti boats in the coastal fishery, following the end of the civil conflict in 2006 and the Government's fisheries management reforms in 2010, has increased (Figure 1) but their harvesting technologies are mostly suboptimal. The efficiency of the coastal industrial vessels is linked to their GRT, although vary substantially with frequent breakdowns and irregular fishing trips.

\subsubsection{Economic Data}

An independent survey was conducted in 2017 to collect data on investment such as costs of vessels, outboard engines and fishing gear and operational costs including food, fuel, crew revenue sharing ratios, and maintenance and repairs. Data on marginal cost of fishing effort, $e$, fixed cost, $f c$, and average unit ex-vessel price, $p$, of the landed wet- and frozen whole-fish by species assemblages for the coastal fleets were collected in October-December 2017. A total of $15 \mathrm{Kru}$ and 15 Fanti boat operators were randomly selected and interviewed at Robertsport beach in Grand Cape Mount, Point 4 beach in Montserrado and Marshall beach in Margibi counties. Cost adjustments were made, to reflect the replacement cost of fixed assets [31].

Industrial fishing agencies were sceptical of the study and generally unwilling to provide economic information. This study relied mostly on information provided by agents, for an industrial vessel of a local fishing firm, who are responsible for the daily operations of the industrial vessel.

The industrial fishery marginal costs information such as costs of fuel and lubricants, food and water, crew's salary, berthing fees and maintenance, other supplies, and the crew share (bonus) in the catch was provided by three key informants and corroborated with fisheries managers at NaFAA. Investment costs obtained included the cost of vessels, fishing gear, documentation and vessel insurance.

The capital value of the vessel incorporates the vessel and its components i.e., engine and equipment for navigation, communication, freezing and cooling on board the vessel. This work assumes the components of a complete set of trawl gear include wires, ropes, and twines, trawl net and otter boards (or solid beam). 
The estimated value of vessels, are based on replacement cost and verified with vessels of similar technical specifications i.e., length overall, GRT and engine capacity [32]. The information was used to calculate annual total cost incurred by the coastal fleets in Liberia.

A random sample of 60 fish sales at the study sites mentioned above was collected to estimate average ex-vessel prices of landings by species assemblages and fleets in the 2016 base-year. The number of sales, weight $(\mathrm{kg})$ and price of the landed fish by species assemblage were recorded. On this basis, the average ex-vessel price (US $\$ \mathrm{~kg}^{-1}$ ) by species assemblage was calculated, for the Kru and Fanti boats (Table 2). Fish price information was also obtained from the key informants, for the industrial fishery and used to estimate ex-vessel price (US\$ kg-1), using a similar procedure (Table 2). A possible reason for the observed price differences $\left(\mathrm{USkg}^{-1}\right.$ ) between the SSF Kru and Fanti boats and the industrial vessels could be due to a different market focus.

Table 2. Summary statistics of ex-vessel prices of the landed wet- and frozen whole-fish for the Kru, Fanti boats and industrial vessels in 2016.

\begin{tabular}{|c|c|c|c|}
\hline Species Assemblage & Statistics & Kru \& Fanti Boats & Industrial Vessels \\
\hline \multirow{4}{*}{$\begin{array}{l}\text { Small pelagic } \\
\left(\mathrm{US} \$ \mathrm{~kg}^{-1}\right)\end{array}$} & Mean & 1.1 & 1.3 \\
\hline & Std Dev & 0.2 & 0.4 \\
\hline & Min & 0.9 & 0.8 \\
\hline & Max & 1.6 & 1.9 \\
\hline Sample (n) & & 10 & 10 \\
\hline \multirow{4}{*}{$\begin{array}{l}\text { Medium pelagic } \\
\quad\left(\mathrm{US} \$ \mathrm{~kg}^{-1}\right)\end{array}$} & Mean & 2.3 & 3.5 \\
\hline & Std Dev & 0.7 & 0.9 \\
\hline & Min & 1.5 & 2.3 \\
\hline & Max & 3.5 & 5.0 \\
\hline Sample (n) & & 15 & 15 \\
\hline \multirow{4}{*}{$\begin{array}{c}\text { Shallow-water } \\
\text { demersal } \\
\left(\mathrm{US} \$ \mathrm{~kg}^{-1}\right)\end{array}$} & Mean & 2.5 & 2.9 \\
\hline & Std Dev & 0.9 & 0.1 \\
\hline & Min & 1.2 & 2.6 \\
\hline & Max & 4.0 & 3.0 \\
\hline Sample (n) & & 15 & 10 \\
\hline \multirow{4}{*}{$\begin{array}{l}\text { Deep-water demersal } \\
\quad\left(\mathrm{US} \$ \mathrm{~kg}^{-1}\right)\end{array}$} & Mean & 3.6 & 4.0 \\
\hline & Std Dev & 1.6 & 0.3 \\
\hline & Min & 2.0 & 3.3 \\
\hline & Max & 7.2 & 4.0 \\
\hline Sample (n) & & 15 & 8 \\
\hline \multirow{4}{*}{$\begin{array}{l}\text { Crustacean } \\
\left(\mathrm{US} \$ \mathrm{~kg}^{-1}\right)\end{array}$} & Mean & 4.0 & 10.2 \\
\hline & Std Dev & 1.1 & 3.1 \\
\hline & Min & 2.2 & 6.0 \\
\hline & Max & 5.0 & 15.0 \\
\hline Sample (n) & & 10 & 8 \\
\hline \multirow{4}{*}{$\begin{array}{l}\text { Large pelagic } \\
\left(\mathrm{US} \$ \mathrm{~kg}^{-1}\right)\end{array}$} & Mean & 1.5 & 1.7 \\
\hline & Std Dev & 0.7 & 0.1 \\
\hline & Min & 0.5 & 1.5 \\
\hline & Max & 3.0 & 1.8 \\
\hline Sample (n) & & 10 & 5 \\
\hline
\end{tabular}




\subsection{Statistical Approach}

\subsubsection{Biological Parameters}

Biomass growth functions were estimated for five species assemblages i.e., small and medium pelagics, shallow-and deep-water demersals and crustaceans. Biomass growth function was not estimated for the large pelagics because the management of these species is undertaken regionally by the International Commission for the Conservation of Atlantic Tunas [4,33]. Therefore, Liberia has no direct control over the stock.

The parameters $\alpha$ and $\beta$ in Equation (4) for the five species assemblages were estimated using linear regression analysis of expression (11). The parameter $\delta$, for the species assemblages, was calculated using the expression $\delta=h / e \times x^{\mu}$ derived from expression (6). Standardized CPUEs, biomasses and $\mu$ were used to calculate average $\delta$ values. The coefficient $d(\delta)$, in the regression analysis, was restricted to the calculated average values for the pelagic and demersal species assemblages following Warui [34], while for the crustaceans it was employed to calculate stock size. For all 5 species assemblages, the values of $b$ and $c$ were estimated. Following this, the explained variable $\Delta y^{\mathrm{s}}{ }_{j}$ was regressed against the explanatory variables $y^{s}{ }_{j t}$ and $e^{\mathrm{s}}{ }_{j t}$, using expression (11).

For the small and medium pelagics, about $56 \%$ and $87 \%$ of the variation in the residuals were explained by the models, while for the shallow- and deep-water demersals about $72 \%$ and $92 \%$ of the variation in the residuals were accounted for (Table 3). For the crustaceans, about $62 \%$ of the variation in the residuals was explained by the model. The $p$-values of the models for all five species assemblages modelled are at a $>0.05$ level of significance (Table 3). This indicates there was not a statistically significant relationship between fishing effort and catch landed. It is important to note that the $p$-values are low because there are few degrees of freedom. The Shapiro-Wilk test coefficients and $p$-values, for all 5 species assemblages, indicate that the residuals are not significantly different from normal (Table 3). After estimating expression (11), $\alpha$ and $\beta$ were calculated (Table 3).

A separate harvesting function per species assemblage and fleet was used. About $97 \%$ of the landed catches are generated from the small and medium pelagics, shallow- and deep-water demersals, and the crustacean species. For these species assemblages, fifteen harvesting functions were estimated, using expression (6).

The catchability coefficient, $\delta$, for the fleets and fisheries, were calculated using expression $\hat{\delta}_{1}=h / e \cdot x^{u}$ derived from expression (6) (Table 4). Note that fishing vessels do not have the same catchability coefficients, even those in the same category. Therefore, $\hat{\delta}_{1}$, which measures the change in the harvest with respect to a change in the vessel type i.e., $\partial h / \partial e=\hat{\delta}_{1} \cdot x^{\mu}$, should be regarded as the catchability of a standardized Kru, Fanti or industrial vessel. 
Table 3. Output of regression analysis on $b, c$ and $d$, normality diagnostic tests and estimates of $\alpha$ and $\beta$.

\begin{tabular}{|c|c|c|c|c|c|c|c|c|c|c|}
\hline \multicolumn{9}{|c|}{ Coefficients } & \multicolumn{2}{|c|}{ Estimates of Alpha \& Beta } \\
\hline Stock & $b$ & $c$ & $d$ & $\mathbf{R}^{2}$ & $p$-Value & $\mathrm{SE}$ & $\begin{array}{l}\text { Shapiro Wilk } \\
\text { Test (w-Value) }\end{array}$ & $\begin{array}{l}\text { Shapiro Wilk } \\
\text { Test ( } p \text {-Value) }\end{array}$ & Alpha $(\alpha)$ & Beta $(\beta)$ \\
\hline Small pelagic & 0.41 & 0.05 & $-9.2 \times 10^{-5}$ & 0.56 & 0.66 & 0.20 & 0.99 & 0.94 & 0.41 & $4.3 \times 10^{-6}$ \\
\hline Medium pelagic & 0.46 & 0.24 & $-6.2 \times 10^{-5}$ & 0.87 & 0.36 & 0.11 & 0.86 & 0.26 & 0.46 & $1.5 \times 10^{-5}$ \\
\hline Shallow-water demersal & 0.41 & 0.20 & $-5.2 \times 10^{-5}$ & 0.72 & 0.53 & 0.05 & 0.91 & 0.50 & 0.41 & $1.1 \times 10^{-5}$ \\
\hline Deep-water demersal & 1.18 & 2.95 & $-1.2 \times 10^{-4}$ & 0.92 & 0.28 & 0.34 & 0.89 & 0.38 & 1.18 & $3.5 \times 10^{-4}$ \\
\hline Crustacean & 1.66 & 13.55 & $-7.1 \times 10^{-5}$ & 0.62 & 0.61 & 0.23 & 0.82 & 0.15 & 1.66 & $9.6 \times 10^{-4}$ \\
\hline
\end{tabular}

Source: Model, Note: $d$ values for small and medium pelagics and shallow- and deep-water demersals are restricted to the calculated average estimates of $\delta$, while estimated $d$ is used for the crustacean.

Table 4. Estimates of catchability coefficients and schooling parameters for the coastal fleets in base-year.

\begin{tabular}{|c|c|c|c|c|}
\hline Species Assemblage & Kru Canoe (1/Boat) & Fanti Boat (1/Boat) & Ind. Vessel (1/Boat) & Schooling Paramete \\
\hline Small pelagic & $5.5 \times 10^{-6}$ & $3.4 \times 10^{-4}$ & $1.54 \times 10^{-4}$ & 0.98 \\
\hline Medium pelagic & $1.6 \times 10^{-5}$ & $1.7 \times 10^{-4}$ & $1.2 \times 10^{-5}$ & 0.98 \\
\hline Shallow-water demersal & $6.0 \times 10^{-5}$ & $4.6 \times 10^{-5}$ & $3.2 \times 10^{-3}$ & 1.00 \\
\hline Deep-water demersals & $2.3 \times 10^{-5}$ & $6.2 \times 10^{-6}$ & $7.04 \times 10^{-3}$ & 1.00 \\
\hline Crustacea & $9.6 \times 10^{-6}$ & $5.3 \times 10^{-7}$ & $2.09 \times 10^{-2}$ & 1.00 \\
\hline Large pelagic & $5.8 \times 10^{-2 *}$ & $3.5 \times 10^{-1 *}$ & $6.57 *$ & 0.00 \\
\hline
\end{tabular}




\subsubsection{Economic Parameters}

In the SSF, $f_{c}$ comprises capital cost including depreciation and interest payment on boat value and equipment, cost of boat, outboard engine and, gear, and license fees. For the industrial vessels, $f_{c}$ includes the capital cost comprised of depreciation and interest payment on the vessel value and gear, vessel, fishing gear, documentation, and vessel insurance. Variable costs are divided into variable costs related to fishing effort and those related to the harvest value i.e., crew share or bonus in the fishing revenues. The Kru boats fish on average 5-6 days week ${ }^{-1}$, i.e., 20 days $^{\text {month }}{ }^{-1}, 10$ months year $^{-1}$, while the Fanti boats fish 20 days month ${ }^{-1}$ for 6 months year ${ }^{-1}$. Kru canoes crew and canoes owners are reported to receive $50 \%$ of the value of harvest while $50 \%$ is reserved for the enterprise' property for operation and investment costs. For the Fanti, it is based on 40:60, i.e., $40 \%$ of the revenue is shared up between the boat's owner and crew and $60 \%$ for the enterprise' property.

Note that while globally crew's remuneration arrangements for most fisheries are based on shared remuneration systems (i.e., the fishing crew is paid a proportion of the fishing revenues or value of the landed catch or profits) [35-44], in the Liberian coastal industrial fishery the crew remuneration is time-based, i.e., fixed monthly salary and a bonus, usually paid through the captain and ranges between $5-10 \%$ of the value of landings. In this study crew's bonus was estimated to be $8 \%$. Industrial vessels on average attempt two 10 days fishing trips month ${ }^{-1}$ for 11 months of the year, and a month for major repairs. The average ex-vessel prices (US\$ $\mathrm{kg}^{-1}$ ), for the wet whole-fish landed by the small-scale fleets and the frozen whole-fish landed by the industrial fleet, were used as unit price estimates (Table 2). The total annual cost parameters estimates and crew sharing ratios, for the coastal fleets, are listed in Table 5).

Table 5. Cost parameter estimates in 2016 base-year.

\begin{tabular}{|c|c|c|c|c|}
\hline Fleet & Crew Share $(\gamma \%)$ & $\begin{array}{c}\text { Variable Cost } \\
\left(v c \text { boat }^{-1} \mathrm{yr}^{-1}\right) \\
\left(\mathrm{US} \$ 1000 \mathrm{boat}^{-1}\right)\end{array}$ & $\begin{array}{c}\text { Fixed Cost } \\
\left(f c \text { boat }^{-1} \mathrm{yr}^{-1}\right) \\
\left(\mathrm{US} \$ 1000 \text { boat }^{-1}\right)\end{array}$ & $\begin{array}{c}\text { Total Cost } \\
\left(\text { boat }^{-1} \mathrm{yr}^{-1}\right) \\
\left(\text { US\$ } 1000 \text { boat }^{-1}\right)\end{array}$ \\
\hline Kru canoe & $50 \%$ & 0.60 & 0.88 & 1.48 \\
\hline Fanti boat & $40 \%$ & 2.65 & 10.64 & 13.29 \\
\hline $\begin{array}{l}\text { Industrial } \\
\text { vessel }\end{array}$ & $8 \%$ * & 143.93 & 329.25 & 473.18 \\
\hline
\end{tabular}

Source: Survey, ${ }^{*}=$ bonus of industrial vessels crew.

\section{Results and Discussion}

\subsection{State of the Coastal Fishery}

Aggregate MSY in the Liberian coastal waters is estimated to be roughly 18,700 tons year ${ }^{-1}$ (Table 6). The shallow-water demersals appear to be overexploited, while biomass estimates for other species assemblages are well above Xmsy levels. MSY estimate for crustacean is now 7100 tons, only' $44 \%$ of the estimated MSY of 1600 tons in 1983 [15]. It should be noted that the estimate in 1983 was based on industrial shrimp fishery, but today most of the crustacean catch is by the Kru who primarily catch shallow water crabs and lobsters. Only a minor portion of crustacean caught in recent years are shrimp. It can thus be assumed that there is a considerable potential to increase shrimp catches. 
Table 6. Stock estimates at the end of 2016.

\begin{tabular}{ccccccc}
\hline Species Assemblage & $\begin{array}{c}\text { MSY } \\
(\mathbf{1 0 0 0} \mathbf{t})\end{array}$ & $\begin{array}{c}\mathbf{X m s y} \\
(\mathbf{1 0 0 0} \mathbf{t})\end{array}$ & $\begin{array}{c}\text { Xmax } \\
\mathbf{( 1 0 0 0 ~} \mathbf{t})\end{array}$ & $\begin{array}{c}\text { Stock } \\
\mathbf{( 1 0 0 0 ~ t )}\end{array}$ & Stock/Xmax & Stock/Xmsy \\
\hline Small pelagic & 9.52 & 46.95 & 93.90 & 68.83 & 0.7 & 1.5 \\
Medium pelagic & 3.56 & 15.41 & 30.82 & 25.75 & 0.8 & 1.7 \\
Shallow-water demersal & 3.91 & 19.16 & 38.32 & 12.87 & 0.3 & 0.7 \\
Deep-water demersals & 0.99 & 1.67 & 3.34 & 3.05 & 0.9 & 1.8 \\
Crustacean & 0.71 & 0.86 & 1.72 & 1.26 & 0.7 & 1.5 \\
\hline & 18.70 & 84.05 & 168.09 & 111.76 & 0.7 & 1.3 \\
\hline
\end{tabular}

Source: Model and Authors 'calculations.

Except for the shallow-water demersals, all fish stocks in the coastal waters of Liberia appear to be underutilized (Table 6). A likely explanation is the prolonged civil conflict, underinvestment in the coastal fisheries, and changes in policy. The conflict prevented the expansion of fishing effort in the SSF [45]. Exits from the coastal industrial fisheries seem to have increased after changes in policy in 2010 when the Liberian Government introduced a zoning regulation (Figure 1). It seems this zoning policy may explain the trawlers poor catch of shrimps today since industrial trawling is prohibited within $6 \mathrm{~nm}$ inshore zone where the main coastal shrimp resources are concentrated [3,5,15]. The Kru canoes, that operate in that zone, catch some crustaceans, i.e., crabs and lobsters, but are inefficient [46], indicating underutilization of this valuable resources. In this case, it would be worthwhile to introduce some changes making it possible to fully exploit these valuable shrimp resources, while at the same time avoiding conflicts in the coastal fisheries.

During the early 1980s, the trawlers in Liberia were allowed to operate outside $3 \mathrm{~nm}$ but in 2010 they had to go outside $6 \mathrm{~nm}$ into deeper waters [3,5]. The trawlers operating today are old ( $\geq 30$ years) and inefficient for trawling in deeper waters [13]. Consequently, the trawlers have been disappearing from the coastal fisheries.

The current state of the small and medium pelagics, deep water demersals and crustacean species assemblages indicate possibilities for new technological investments in the fishery to utilize the harvesting possibilities. The current depressed state of the shallow-water demersals suggests a need for stricter regulations, particularly for the Kru boats that mostly seem to thrive under open access.

\subsection{Coastal Fleets Economics}

In 2016, the small-scale and the industrial fisheries appear to have been profitable (Table 7). Total profits are estimated at around US\$ 7.2 million with the Kru and Fanti boats accounting for nearly $99 \%$. Estimated profits boat ${ }^{-1}$ were around US\$ 510 for a typical Kru canoe, US\$ 8000 for a Fanti boat and US\$18,200 for an industrial vessel. While estimated profits as a share of revenues were reasonable for the coastal fleets, the average return on investments (ROIs) appear to be particularly encouraging $\geq 68 \%$ in the SSF. The industrial vessels were less profitable, which may explain the lack of investment in the coastal industrial fishery in Liberia.

Table 7. Estimated economic outcome of the fishery end of 2016.

\begin{tabular}{cccccccc}
\hline & \multicolumn{4}{c}{ All Vessel } & \multicolumn{2}{c}{ Vessel $^{-1}$} \\
\hline Economics Status & Total & Kru & Fanti & Industrial & Kru & Fanti & Industrial \\
\hline Revenue (US\$ 1000) & $39,012.9$ & $12,562.0$ & $24,315.1$ & 2135.8 & 3.97 & 35.5 & 534.0 \\
Cost (US\$ 1000) & $31,854.3$ & $10,962.2$ & $18,829.0$ & 2063.1 & 3.47 & 27.5 & 515.8 \\
Profits (US\$ 1000) & 7158.6 & 1599.7 & 5486.1 & 72.7 & 0.51 & 8.0 & 18.2 \\
Profits/revenue & 0.18 & 0.13 & 0.23 & 0.03 & 0.13 & 0.23 & 0.03 \\
Return on investment & 0.70 & 0.68 & 0.81 & 0.06 & 0.68 & 0.81 & 0.06 \\
\hline
\end{tabular}

Source: Model and Authors 'calculations. 
In general, world fisheries have been moving towards industrialization i.e., bigger motorized vessels are more effective $[47,48]$, but this does not appear to be the case with the industrial fishery in Liberia. The introduction and increased enforcement of zoning regulations seem to have changed the profitability of the coastal fleet, benefiting the SSF by increasing their access to the coastal resources. This regulatory action appears to be in line with SDG 14B, which encourages states to protect the access rights of SSF [8].

Limited access to critical fishing inputs, i.e., fishing nets, outboard motors, big forest trees traditionally used to build the Fanti boats (as the length of these boats is determined by the size of the forest tree used for the keel), makes it somewhat difficult to invest in new boats and equipment, according to reports from NaFAA and Fanti fishermen. This may explain the current development trend in the Fanti fishery, as it would otherwise be expected for a profitable fishery.

Although the Fanti boats appear to be performing better relative to the Kru canoes and the industrial vessels, this does not imply that replacing all other vessels with the Fanti is a viable policy option. The vessel groups use different harvesting technologies and target different species. Such change may therefore be technically infeasible. Differences in profitability between vessel groups may have more to do with the profitability of harvesting different target species. It seems therefore that the overall best feasible utilization of coastal fishery resources in Liberia would be some combination of these fleets or the introduction of new technologies.

\subsection{Dynamic Fisheries Policy}

The evolution of the fisheries depends on the fisheries policy and how it is implemented, i.e., the number and types of vessels that are employed in the fishery and how their activities are regulated. Four fisheries policies scenarios (FPS) were examined: maintaining 2016 fishing effort levels, business as usual (BAU); optimal and realistic optimal policies. The average annual interest rate in Liberia was $13 \%$ at the end of 2016 [49]. This average interest rate is adopted in this analysis, although it may seem high for the analysis of the maximum net benefit.

\subsubsection{Maintaining 2016 Fishing Effort}

Under this fishery policy, we assessed what would happen if the 2016 initial biomasses $\left(x_{\mathrm{o}}\right)$, of the stocks modelled, and the number of Kru, Fanti, and industrial vessels are unchanged. The biomass and catch of small pelagics decline by about a third in the first four years but stabilize thereafter. The medium pelagic show a similar trend (Figure 2a). Once these species assemblages reached sustainable levels (equilibrium), they are just above their respective Xmsy.

Under this FPS, the shallow- and deep-water demersals show signs of recovery in the beginning and thereafter become stable ending up far above their 2016 levels (Figure 2b). The crustaceans initially decline moderately and stabilize after the 5 th year (Figure 2c). This species assemblage is above its Xmsy after it reaches sustainable levels. Under this FPS, the aggregate profits decrease along with the stocks in the beginning years and afterwards become stable (Figure 2d). The Kru boats realized the most profits, after seven years of control.

This FPS is unlikely to materialize because the individual boats enjoy substantial profits and so there are incentives for expansion in the fisheries, i.e., invest in new boats and improvements of existing vessels. There are signs of this occurring already in 2019 according to reliable informal reports. 


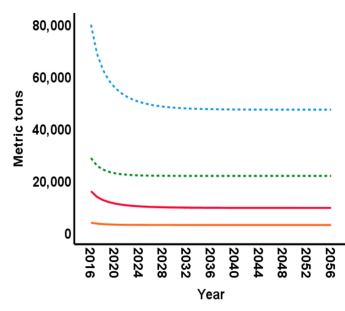

(a)

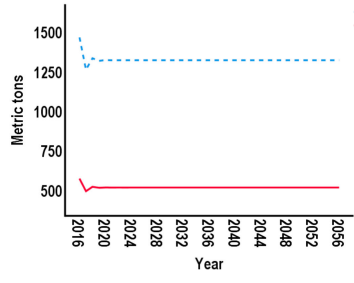

(c)
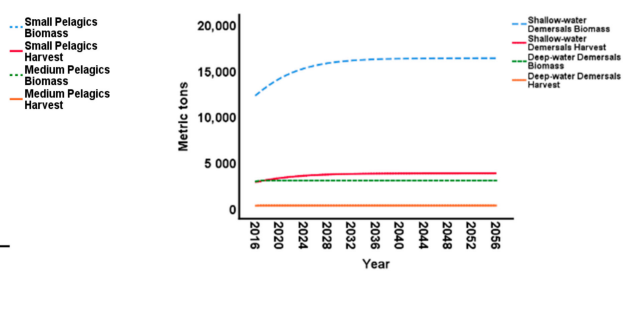

(b)
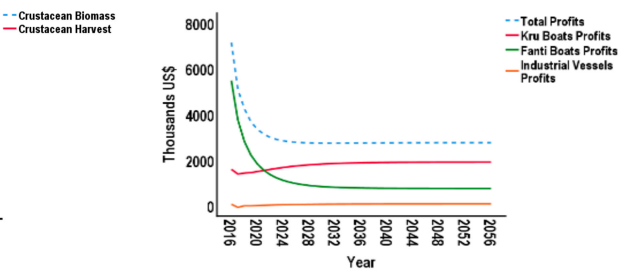

(d)

Figure 2. (a) Evolution of small and medium pelagic; (b) Evolution of shallow-and deep-water demersals; (c) Evolution of the crustacean; (d) Evolution of profits. Source: Model.

\subsubsection{Business as Usual}

The decision rule used here to assess the BAU FPS was if profits are greater than zero then they increase (i.e., average $\Delta$ effort), or else they decrease (average $\Delta$ effort). This rule was necessary to reflect the behaviour of commercial fleets in response to positive or zero profits by increasing or reducing fishing effort, based on historical changes in effort.

The small and medium pelagics fall far below their 2016 levels (Figure 3a). While the medium pelagics remain above their Xmsy, the small pelagics are 3\% below their Xmsy. The sustainable yields of these species revealed similar trends. The shallow-water demersals fall below their 2016 levels to nearly $54 \%$ below Xmsy, whereas the deep-water demersals showed a similar trend but remain far above Xmsy (Figure 3b). The crustaceans decline severely below the 2016 levels and sustainable harvest also but remain $45 \%$ above Xmsy (Figure 3c). Aggregate profits decrease to zero (Figure 3d). Because of this, there will be no incentives for additional entries into the fisheries.
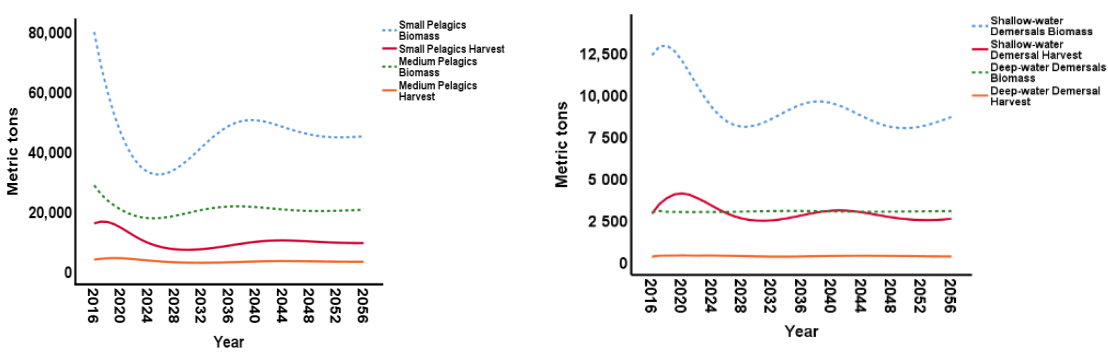

(a)

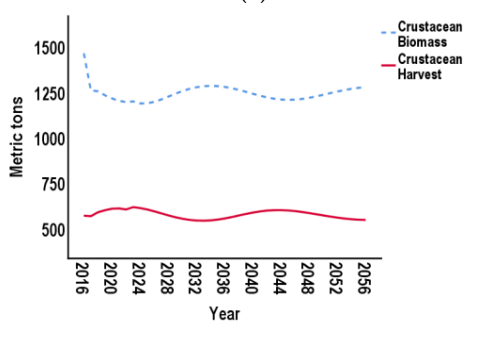

(c)

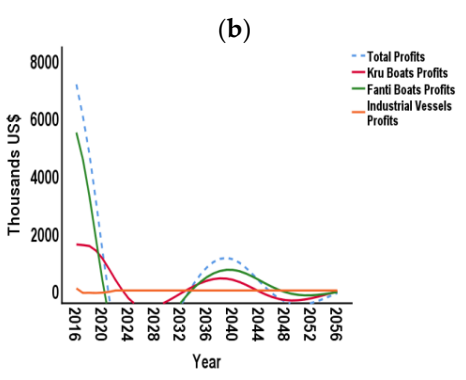

(d)

Figure 3. (a) Evolution of small and medium pelagics; (b) Evolution of shallow- and deep-water demersals; (c) Evolution of the crustacean; (d) Evolution of profits. Source: Model. 


\subsubsection{Maximum Net Benefits Policy}

The objective, under this FPS, is to maximize the present value of profits. To locate the optimal dynamic fishery policies, the fundamental principle of dynamic optimization in fisheries was employed, using an iteration procedure [20-22].

To optimize profits in the coastal fisheries in Liberia, the model shows that the current number of boats should be reduced by around $58 \%$ for the Kru and $26 \%$ for the Fanti, whereas the industrial vessels should be increased by about $75 \%$ (Figure $4 \mathrm{a}$ ). This large reduction in effort compared to the current situation has to do with the high costs and inefficiency of the vessels, suggesting in an optimal strategy of fewer vessels and much higher CPUE. This will lead to a speedy restoration of the shallow-water demersals and generation of substantial profits (Figure $4 b-d$ ). The biomass of all species assemblages is above their respective Xmsy.

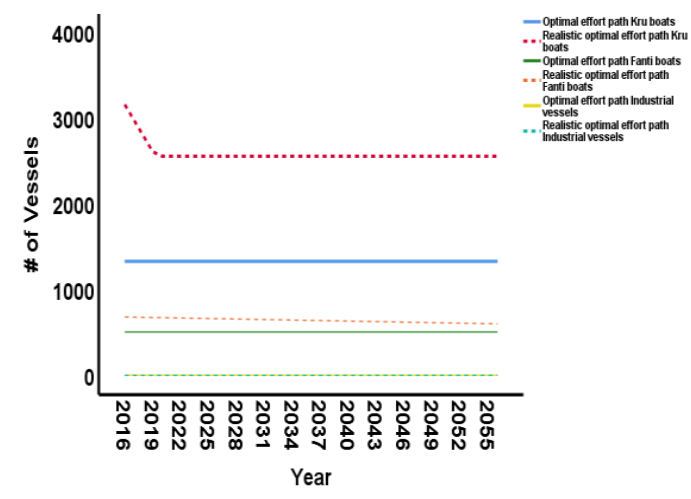

(a)



(c)

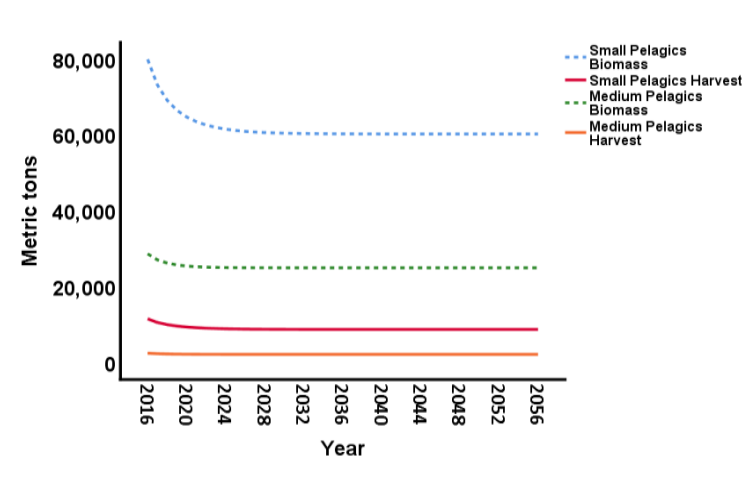

(b)

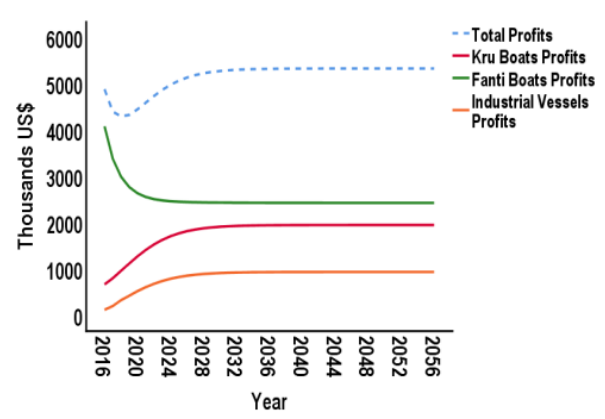

(d)

Figure 4. (a) Optimal and feasible Kru, Fanti and industrial effort paths; (b) Small and medium pelagics; (c) Shallow- and deep-water demersals and crustacean.; (d) Profits. Source: Model.

However, a realistic feasible optimal adjustment path which incorporates food and nutrition security and socio-economic and environmental considerations [47] might be more practical for Liberia's coastal fisheries. This realistic optimal fisheries policy indicates around 19\% reduction of the current number of Kru canoes but no cut for the Fanti and industrial vessels and an overall reduction of $16 \%$ (Table 8). While profits vessel ${ }^{-1}$ for the small-scale fleets increase considerably, the total sustainable profits increased by nearly $29 \%$ compared to its 2016 (Figure 4d). Note that some loss of profits will occur during the early years of the fisheries control, due to sunken costs. 
Table 8. Long-term economic highlights of the fisheries policies scenarios (FPS).

\begin{tabular}{|c|c|c|c|c|c|c|c|c|}
\hline \multirow[b]{2}{*}{ Policy Scenario } & \multicolumn{3}{|c|}{ Employed Boats } & \multirow{2}{*}{$\begin{array}{c}\text { Present Value } \\
\text { of Profits } \\
\text { (million US\$) }\end{array}$} & \multirow{2}{*}{$\begin{array}{c}\text { Long-Term Annual } \\
\text { Profits } \\
\text { (million US\$) }\end{array}$} & \multicolumn{3}{|c|}{ Profits Boat $^{-1}$ (1000 US\$) } \\
\hline & Kru & Fanti & Trawler & & & Kru & Fanti & Ind. \\
\hline Maintaining 2016 effort & 3165 & 685 & 4 & 33.1 & 2.8 & 0.6 & 1.1 & 21.6 \\
\hline BAU & 4710 & 687 & 0 & 12.8 & -15.0 & 0.0 & 0.0 & 0.0 \\
\hline Maximum net benefits & 1334 & 510 & 7 & 41.8 & 5.3 & 1.5 & 4.8 & 134.7 \\
\hline Realistic optimal & 2561 & 685 & 4 & 35.8 & 3.6 & 0.9 & 1.6 & 63.2 \\
\hline
\end{tabular}

A comparison of the long-term features, of the three FPSs assessed, indicate fleet size under the "BAU" is the greatest (Table 8). The present value of profits, sustainable long-run profits, and the profits boat $^{-1}$ are highest under the maximum net benefits FPS but lowest under the "BAU" fisheries policy.

The maximum net benefits FPS indicates that the current fleet size should be reduced, even though the stocks are currently underutilized (Table 6). This is due to the low effectiveness and high cost of the current fleet. Note that the present value estimates for all four FPS simulated are sensitive to the rate of discount used. Discount rates below 13\% would naturally generate higher present value estimates.

However, while it is possible to calculate the optimal combination of fleets for the Liberian coastal fisheries, it is currently an unrealistic policy option to implement. This is because of the crucial role of SSF in Liberia in terms of food security and poverty alleviation as reported elsewhere [50-56], the imperfect substitutability between the coastal fleets, the potentially detrimental effects of the poorly performing trawl fishery [28,57-61], and the poor state of the Liberian economy evidence by widespread poverty and limited employment opportunities [62].

A fisheries policy which considers maximizing the present value of profits, employment of the marginalized small-scale fishers, and the marine environment seem to be realistically optimal [63,64]. A major drawback, however, is the short-term costs (socio-economic) that are necessary to reduce the excess fishing capacity [63]. Note the trawlers are neither efficient nor profitable but technical infeasibility of harvesting the same resources with the Kru canoes make the trawlers a viable part of the coastal fisheries in Liberia. There is a need, therefore, for the coastal fisheries to undergo major technological development and investments as well as improved management.

\subsection{Model Structural Uncertainties}

Effects of non-harvesting anthropogenic alterations, technological change, and socio-economic and environmental fluxes were not incorporated in the bio-economic model, because the effects of structural uncertainty are not amenable to standard modelling approaches [65].

The economic downturn and prevalent poverty in Liberia [62] and harvesting externalities due to excessive fishing effort and disruptions between SSF and industrial fisheries resulting from competition for the same species may greatly affect the coastal marine fisheries. It is likely that these factors may have negative effects on the results (benefits) from the fisheries policies analyzed here. Lack of reliable data, however, impeded analysis of the impacts of these factors. Further analysis is required to shed light on the effects of environmental and other non-fishing anthropogenic influences on Liberian fisheries.

Catchability, marginal cost of fishing, and price of the landed catch, which may vary as the number of vessels in the fisheries, marine environment, and fish market conditions change, are assumed constant. Fishing grounds, which may change in accordance with seasonal fluctuations in the stocks' availability and overfishing of inshore stocks, in reality, are assumed unchanged. A constant discounting rate is assumed in this analysis but time preferences of individuals and groups, as well as their determinants, evolve overtime as societies change [66].

A key assumption in our fisheries policy analysis is that all the coastal fisheries vessels cooperate to realistically optimize the overall benefits of the fishery resources. Therefore, in some fisheries policy scenarios, the benefits of some fleets were optimized at the expense of others following Cheung and Sumaila [63]. While this assumption may influence the optimal fleet structure in the fisheries, the overall trade-offs, presented in this analysis, should remain valid $[65,67]$. 


\section{Conclusions and Policy Recommendation}

This analysis set out to shed light on the state of the coastal fisheries in Liberia, actions taken by the Government to effectively regulate harvesting to produce at MSY, and secure access rights for the SSF fishers aligned with SDG 14 targets 14.4 and $14 \mathrm{~B}$.

The bio-economic model indicates that the shallow water demersals are overfished while most other species are not fully exploited. The most likely explanation for the observed under exploitation is the civil conflict in Liberia and the 2010 policy of extending the exclusion zone for trawlers. The coastal fisheries were profitable in 2016 but the distribution of profits was skewed to the small-scale fleets. ROIs were $>67 \%$ for the Kru and Fanti boats, while it was much lower $(<7 \%)$ for the industrial vessels. The poor performance of the coastal industrial fishery can most probably be attributed to the introduction of zoning regulation in 2010, accompanied by increased enforcement. This seems to have led to a redistribution of benefits from industrial to small-scale fishers and to changes in the development of the coastal fleets.

It seems the Liberian Government zoning regulatory action taken in 2010 supplemented by increased enforcement has been successful in attaining certain parts of SDG 14 and targets 14.4 and $14 \mathrm{~B}$, in terms of stocks rebuilding and increasing SSF access to coastal resources but probably at the expense of economic efficiency.

There has in particular been an increase in the Kru fleet, which certainly is a contributing factor to the overfishing of the shallow water demersals that are primarily targeted by this fleet. Other stocks are underexploited, possibly because the SSF does not possess the appropriate technology to harvest other species complexes.

The results from dynamic simulation indicate that the current fleet size will over time lead to some stock decline in all species. Since both the Kru and the Fanti are currently operating with profits, there appear to be substantial incentives for new investments in the coastal fisheries. Regulatory actions, especially for the Kru and Fanti fleets, is therefore needed to manage the fishery sustainably. Designing an effective policy is however quite challenging.

The three coastal fleets are designed differently and employ different harvesting technologies targeting different species in different depths and zones. Some mixture of the different types or the introduction of new technology as the current fleet structure seems unlikely to effectively utilize the opportunities to expand fisheries of deep-water demersal and crustacean, i.e., crabs and lobsters as well as shrimp. In this case, it seems introducing some changes to make it possible to exploit the valuable coastal shrimp resources, while at the same time preventing interference between the industrial and SSF which may lead to the conflict would be worthy. A successful policy must address the issue of the SDG's, access for SSF's, sustainable management as well as the appropriate technology for the utilization of the different categories of marine species available in the Liberian EEZ. This is a considerable challenge.

Finally, this analysis acknowledges that the harvesting function (expression 6), assumed here, restricts effort elasticity to unity i.e., $1 \%$ increase in effort leads to a $1 \%$ increase in the profits. More flexible functional forms exist, e.g., the Cobb-Douglas production function e.g., [68]. Further, surplus production models are restrictive in their assumptions and do not include factors that have been shown to be important to management, e.g., the biological relationship between the size or age composition of the stocks, e.g., [69]. Recent analyses e.g., [70,71] have shown, that when the age-structured information is considered, optimal harvesting strategies may be different from those found when optimization is based on conventional surplus production models. The simplicity of the surplus production model makes it applicable in cases where data is scarce. This analysis is an example of such a case where a bio-economic model can be estimated and realistic optimal harvesting paths identified in a complex but data-poor fisheries context.

Author Contributions: Conceptualization, A.S.J.; Methodology, A.S.J.; Software, A.S.J.; Validation, D.M.K., T.T. and O.K.; Formal Analysis, A.S.J.; Investigation, A.S.J.; Resources, NaFAA through the framework of the Sectorial Support Program of the Sustainable Fisheries Partnership Agreement between Liberia and the EU and 
the UNESCO-Fisheries Training Program; Data Curation, A.S.J.; Writing-Original Draft Preparation, A.S.J.; Writing-Review \& Editing, A.S.J., D.M.K., T.T. and O.K.; Visualization, D.M.K., T.T. and O.K.; Supervision, D.M.K., T.T. and O.K.; Project Administration, T.T. and D.M.K.; Funding Acquisition, D.M.K. and T.T. All authors have read and agreed to the published version of the manuscript.

Funding: This research was funded by the National Fisheries and Aquaculture Authority of Liberia, within the framework of the Sectorial Support Program of the Sustainable Fisheries Partnership Agreement between Liberia and the EU and the UNESCO affiliated GRO-Fisheries Training Program in Iceland.

Acknowledgments: All the fishermen who provided valuable information through interviews, research assistants, as well as anonymous reviewers of an earlier manuscript, are hereby acknowledged.

Conflicts of Interest: The authors declare no conflict of interest.

\section{References}

1. Belhabib, D.; Sumaila, U.R.; Pauly, D. Feeding the poor: Contribution of West African fisheries to employment and food security. Ocean Coast. Manag. 2015, 111, 72-81. [CrossRef]

2. World Bank. GNI per Capita, Atlas Method (Current US)-Liberia. Available online: https://data.worldbank. org/indicator/NY.GNP.PCAP.CD?locations=LR (accessed on 20 November 2019).

3. Ssentongo, G.W. Marine Fishery Resources of Liberia: A Review of Exploited Fish Stocks; FAO: Rome, Italy, 1987.

4. MRAG. Fisheries Stock Assessment; Report produced under WARFP/BNF Contract 11/001; MRAG: Liberia, West Africa, 2014.

5. Ministry of Agriculture. Regulations Relating to Fisheries, Fishing and Related Activities for the Marine Fisheries Sector in the Republic of Liberia; Ministry of Agriculture: New Delhi, India, 2010.

6. Arnason, R. Loss of economic rents in the global fishery. J. Bioecon. 2011, 13, 213-232. [CrossRef]

7. World Bank. The Sunken Billions Revisited: Progress and Challenges in Global Marine Fisheries; World Bank Publications: Washington, DC, USA, 2017.

8. Rosa, W. (Ed.) Transforming Our World: The 2030 Agenda for Sustainable Development. In A New Era in Global Health; Springer Publishing Company: New York, NY, USA, 2017.

9. Work Bank. Economic, Environmental, and Social Evaluation of Africa's Small-Scale Fisheries. 95557; Work Bank: Washington, DC, USA, 2015.

10. Chu, J.; Garlock, T.M.; Sayon, P.; Asche, F.; Anderson, J.L. Impact evaluation of a fisheries development project. Mar. Policy 2017, 85, 141-149. [CrossRef]

11. Drammeh, O.K.L. The Fisheries Subsector. In Ministry of Agriculture Comprehensive Assessment of the Agriculture Sector; Volume 2.1: Subsector, Reports; IFAD: Rome, Italy; World Bank: Washington, DC, USA; FAO: Rome, Italy, 2007; pp. 169-188.

12. MRAG. Fisheries Governance Diagnostic Study; MRAG: Liberia, West Africa, 2013.

13. Ministry of Agriculture. Fisheries and Aquaculture Policy and Strategy; Ministry of Agriculture: Monrovia, Liberia, 2014.

14. Virdin, J.; Kobayashi, M.; Akester, S.; Vegh, T.; Cunningham, S. West Africa's coastal bottom trawl fishery: Initial examination of a trade in fishing services. Mar. Policy 2019, 100, 288-297. [CrossRef]

15. Shotton, R. A Bioeconomic Analysis of the Liberian Shrimp Fishery and a Review of other Marine Fisheries in Liberia; International Finance Corporation: Washington, DC, USA, 1983.

16. Jueseah, A. Economic and Management Implications of the Implementation of an IVQ Regime in the Industrial Offshore Fisheries Sector in Liberia. Master's Thesis, Norwegian College of Fishery Science (NCFS), University of Tromsø (UiT), Tromsø, Norway, 2012.

17. World Bank. Africa-First Phase of West Africa Regional Fisheries Program Project; ICR4008; World Bank: Washington, DC, USA, 2017; (unpublished report).

18. World Bank. West Africa Regional Fisheries Program, Project Appraisal Document (PAD); World Bank: Washington, DC, USA, 2009.

19. Anderson, L.G. The Economics of Fisheries Management/Lee G. Anderson; Johns Hopkins University Press: Baltimore, MD, USA, 1977.

20. Anderson, L.G.; Seijo, J.C. Bioeconomics of Fisheries Management, 1st ed.; Wiley-Blackwell: Ames, IA, USA, 2010.

21. Bjørndal, T.; Munro, G. The Economics and Management of World Fisheries, 1st ed.; Oxford University Press: Oxford, UK, 2012. 
22. Clark, C.W. Mathematical Bioeconomics: The Optimal Management of Renewable Resources, 1st ed.; John Wiley \& Sons Inc.: New York, NY, USA, 1976.

23. Gordon, H.S. The Economic Theory of a Common-Property Resource: The Fishery. J. Politi-Econ. 1954, 62, 124-142. [CrossRef]

24. Scott, A. The Fishery: The Objectives of Sole Ownership. J. Political Econ. 1955, 63, 116-124. [CrossRef]

25. Volterra, V. Fluctuations in the Abundance of a Species considered Mathematically1. Nat. Cell Biol. 1926, 118, 558-560. [CrossRef]

26. Schaefer, M.B. Some Aspects of the Dynamics of Populations Important to the Management of Commercial Marine Species. Inter-Am. Tropical Tuna Comm. Bull. 1954, 1, 27-56.

27. Comitini, S.; Huang, D.S. A Study of Production and Factor Shares in the Halibut Fishing Industry. J. Politi-Econ. 1967, 75, 366-372. [CrossRef]

28. Watling, L.; Norse, E.A. Disturbance of the Seabed by Mobile Fishing Gear: A Comparison to Forest Clearcutting. Conserv. Biol. 1998, 12, 1180-1197. [CrossRef]

29. Zhang, J.; Smith, M.D. Estimation of a Generalized Fishery Model: A Two-Stage Approach; SSRN Scholarly Paper ID 980756; Social Science Research Network: Rochester, NY, USA, 2009.

30. Arnason, R.; MRAG. International University to Assist the Fisheries Management Office of the Bureau of National Fisheries (BNF), Republic of Liberia-Final Report. 2016; (unpublished report).

31. Yeboah, D.A. Use of Capital Income in Artisanal Fisheries: A Case Study of Boat Owners in 1997 Elmina, Ghana; Programme for the Intezrated Development of Artisanal Fisheries in West Africa; Food and Agriculture Organization of the United Nations: Cotonou, Benin, 1997; p. 23.

32. Marine. Maritime Sales. Available online: http://www.maritimesales.com/Fishing\%20Vessels.htm (accessed on 1 February 2018).

33. International Convention for the Conservation of Atlantic Tunas. Available online: https://www.iccat.int/en/ index.asp (accessed on 20 November 2020).

34. Warui, S.W. Optimal Management Policy for the Kenyan Marine Artisanal Fishery. Ph.D. Thesis, University of Iceland, Reykjavik, Iceland, 2014.

35. Acheson, J.M. Anthropology of Fishing. Annu. Rev. Anthr. 1981, 10, 275-316. [CrossRef]

36. Anderson, L.G. The Share System in Open-Access and Optimally Regulated Fisheries. Land Econ. 1982, 58, 435. [CrossRef]

37. Guillen, J.; Boncoeur, J.; Carvalho, N.; Frangoudes, K.; Guyader, O.; Macher, C.; Maynou, F. Remuneration systems used in the fishing sector and their consequences on crew wages and labor rent creation. Marit. Stud. 2017, 16, 1-36. [CrossRef]

38. Guillen, J.; Macher, C.; Merzéréaud, M.; Boncoeur, J.; Guyader, O. Effects of the Share Remuneration System on Fisheries Management Targets and Rent Distribution. Mar. Resour. Econ. 2015, 30, 123-138. [CrossRef]

39. Matthiasson, T. Fixed Wage or Share: Contingent Contract Renewal and Skipper Motivation. SSRN 1997. [CrossRef]

40. McConnell, K.E.; Price, M.K. The lay system in commercial fisheries: Origin and implications. J. Environ. Econ. Manag. 2006, 51, 295-307. [CrossRef]

41. Platteau, J.; Nugent, J. Share contracts and their rationale: Lessons from marine fishing. J. Dev. Stud. 1992, 28. [CrossRef]

42. Pham, T.T.T.; Flaaten, O.; Nguyen, T.K.A.; Thuy, P.T.T.; Anh, N.T.K. Remuneration Systems and Economic Performance: Theory and Vietnamese Small-scale Purse Seine Fisheries. Mar. Resour. Econ. 2013, 28, $19-41$. [CrossRef]

43. Tietze, U.; Prado, J.; Ry, J.-M.L.; Lasch, R. Techno-Economic Performance of Marine Capture Fisheries; FAO: Rome, Italy, 2001.

44. Zoeteweij, H. FAO Fisheries and Aquaculture Department-The Economics of Fisheries; Proceedings of a Round Table Organized by the International Economic Association, Sponsored by FAO; FAO: Rome, Italy, 1956.

45. Belhabib, D.; Subah, Y.; Broh, N.T.; Jueseah, A.S.; Nipey, J.N.; Boeh, W.Y.; Copeland, D.; Zeller, D.; Pauly, D. When 'Reality Leaves a Lot to the Imagination': Liberian Fisheries from 1950 to 2010. In Fisheries Center; The University of British Columbia: Vancouver, BC, Canada, 2013.

46. Jueseah, A.S.; Kristofersson, D.M.; Knutsson, O.; Tómasson, T. Technical efficiency and profitability analysis of coastal small-scale fisheries in Liberia. (unpublished; manuscript in preparation). 
47. FAO. Meeting the Sustainable Development Goals; The State of World Fisheries and Aquaculture: Rome, Italy, 2018.

48. Pauly, D.; Watson, R.; Alder, J. Global trends in world fisheries: Impacts on marine ecosystems and food security. Philos. Trans. R. Soc. B Biol. Sci. 2005, 360, 5-12. [CrossRef]

49. Central Bank of Liberia. Central Bank of Liberia-Annual Report 2017; Central Bank of Liberia: Monrovia, Liberia, 2017.

50. Béné, C.; Hersoug, B.; Allison, E.H. Not by Rent Alone: Analysing the Pro-Poor Functions of Small-Scale Fisheries in Developing Countries. Dev. Policy Rev. 2010, 28, 325-358. [CrossRef]

51. Camp, E.V.; Larkin, S.L.; Ahrens, R.N.; Lorenzen, K. Trade-offs between socioeconomic and conservation management objectives in stock enhancement of marine recreational fisheries. Fish. Res. 2017, 186, 446-459. [CrossRef]

52. Cunningham, S.; Neiland, A. Investigating the Linkages between Fisheries, Poverty and Growth: Policy Brief Report by IDDRA for DFID Technology. Available online: https://www.slideshare.net/cpwfbfp/linkagesbetween-fisheries-poverty-and-growth-policy-brief (accessed on 22 June 2020).

53. FAO (Ed.) Increasing the Contribution of Small-Scale Fisheries to Poverty Alleviation and Food Security; FAO Technical Guidelines for Responsible Fisheries 10; Food and Agriculture Organization of the United Nations: Rome, Italy, 2005.

54. Hicks, C.C.; Cohen, P.J.; Graham, N.A.J.; Nash, K.L.; Allison, E.H.; D’Lima, C.; Mills, D.J.; Roscher, M.; Thilsted, S.H.; Thorne-Lyman, A.L.; et al. Harnessing global fisheries to tackle micronutrient deficiencies. Nat. Cell Biol. 2019, 574, 95-98. [CrossRef] [PubMed]

55. Isaacs, M. Recent progress in understanding small-scale fisheries in Southern Africa. Curr. Opin. Environ. Sustain. 2012, 4, 338-343. [CrossRef]

56. Neiland, A.E.; Cunningham, S.; Arbuckle, M.; Baio, A.; Bostock, T.; Coulibaly, D.; Gitonga, N.K.; Long, R.; Sei, S. Assessing the Potential Contribution of Fisheries to Economic Development-The Case of Post-Ebola Sierra Leone. Nat. Resour. 2016, 7, 356-376. [CrossRef]

57. Alverson, D.L.; Freeberg, M.H.; Murawski, S.A.; Pope, J.G. (Eds.) A Global Assessment of Fisheries Bycatch and Discards; FAO Fisheries Technical Paper 339; Food and Agriculture Organization of the United Nations: Rome, Italy, 1994.

58. Dayton, P.K.; Thrush, S.F.; Agardy, M.T.; Hofman, R.J. Environmental effects of marine fishing. Aquat. Conserv. Mar. Freshw. Ecosyst. 1995, 205-232. [CrossRef]

59. Hall, S.J. The Effects of Fishing on Marine Ecosystems and Communities; Fish Biology and Aquatic Resources Series 1; Blackwell Science: Oxford, UK; Blackwell Science: Malden, MA, USA, 2000.

60. Kumar, B.; Deepthi, G. Trawling and By-Catch: Implications on Marine Ecosystem. Curr. Sci. 2006, 90, 922-931.

61. Thrush, S.F.; Dayton, P.K. Disturbance to Marine Benthic Habitats by Trawling and Dredging: Implications for Marine Biodiversity. Annu. Rev. Ecol. Syst. 2002, 33, 449-473. [CrossRef]

62. World Bank. LIBERIA. 2018. Available online: http://pubdocs.worldbank.org/en/733441492188161968/mpolbr.pdf (accessed on 20 October 2018).

63. Cheung, W.W.L.; Sumaila, U.R. Trade-offs between conservation and socio-economic objectives in managing a tropical marine ecosystem. Ecol. Econ. 2008, 66, 193-210. [CrossRef]

64. Daw, M.T.; Coulthard, S.; Cheung, W.W.L.; Brown, K.; Abunge, C.; Galafassi, D.; Peterson, G.D.; McClanahan, T.R.; Omukoto, J.O.; Munyi, L. Evaluating Taboo Trade-Offs in Ecosystems Services and Human Well-Being. Proc. Natl. Acad. Sci. USA 2015, 112, 6949-6954. [CrossRef]

65. Charles, A.T. Living with uncertainty in fisheries: Analytical methods, management priorities and the Canadian groundfishery experience. Fish. Res. 1998, 37, 37-50. [CrossRef]

66. Hernuryadin, Y.; Kotani, K.; Kamijo, Y. Time Preferences between Individuals and Groups in the Transition from Hunter-Gatherer to Industrial Societies. Sustainability 2019, 11, 395. [CrossRef]

67. Ludwig, D.; Hilborn, R.; Walters, C. Uncertainty, Resource Exploitation, and Conservation: Lessons from History. Science 1993, 260, 17-36. [CrossRef] [PubMed]

68. Garza-Gil, M.D.; Varela-Lafuente, M.M.; Surĺs-Regueiro, J.C. European hake fishery bioeconomic management (southern stock) applying an effort tax. Fish. Res. 2003, 60, 199-206. [CrossRef]

69. Beverton, R.J.H.; Holt, S.J. On the dynamics of exploited fish populations. Fish. Investig. 1957, 19, 1-533. 
70. Tahvonen, O. Economics of harvesting age-structured fish populations. J. Environ. Econ. Manag. 2009, 58, 281-299. [CrossRef]

71. Da-Rocha, J.-M.; Gutiérrez, M.-J.; Antelo, L.T. Selectivity, Pulse Fishing and Endogenous Lifespan in Beverton-Holt Models. Environ. Resour. Econ. 2013, 54, 139-154. [CrossRef]

Publisher's Note: MDPI stays neutral with regard to jurisdictional claims in published maps and institutional affiliations.

(C) 2020 by the authors. Licensee MDPI, Basel, Switzerland. This article is an open access article distributed under the terms and conditions of the Creative Commons Attribution (CC BY) license (http://creativecommons.org/licenses/by/4.0/). 